\title{
Validation of the clinical frailty score (CFS) in French language
}

Paul Abraham ${ }^{1,2,3^{*}} \mathbb{D}$, Delphine S. Courvoisier ${ }^{4}$, Cedric Annweiler ${ }^{5,6}$, Cliff Lenoir ${ }^{1}$, Thomas Millien $^{1,3}$, Francoise Dalmaz ${ }^{1}$, Hans Flaatten ${ }^{7}$, Rui Moreno ${ }^{8}$, Steffen Christensen ${ }^{9}$, Dylan W. de Lange ${ }^{10}$, Bertrand Guidet ${ }^{11,12,13}$, Karim Bendjelid ${ }^{1,3}$, Bernhard Walder ${ }^{14}$ and Bernardo Bollen Pinto ${ }^{14}$

\begin{abstract}
Background: Very old critical ill patients are a rapid expanding group. To better understand the magnitude of the challenges involved in intensive care practice for an ageing population and discuss a rational allocation of resources, healthcare practitioners need a reliable evaluation of frailty. In order to promote the adequate use of the Clinical Frailty Scale (CFS) in a wider panel of countries, we aimed to develop, validate and characterise a French (FR) version from the original English (EN) CFS.
\end{abstract}

Methods: We included participants recruited prospectively for the observational "The very old intensive care patient: A multinational prospective observation study" (VIP Study) at Geneva University Hospitals (FR speaking hospital). A FR version of the CFS was obtained by translation (EN- > FR) and back translation (FR- $>$ EN). The final CFS-FR was then evaluated twice on the same participants with at least a 2-week interval by FR-speaking doctors and nurses.

Results: Inter-rater reliability was 0.87 (95\%Cl: $0.76-0.93$ ) between doctors for the original CFS version and 0.76 (95\%Cl: $0.57-0.87$ ) between nurses for the FR version. Inter-rater variability between doctor and nurse was 0.75 (95\%Cl: $0.56-0.87)$ for the original version, and $0.73(95 \% \mathrm{Cl}: 0.52-0.85)$ for the FR version.

Test-retest (stability) with the original vs the FR version was 0.86 (95\% Cl: $0.72-0.93)$ for doctors and 0.87 (95\%Cl: 0.76-0.93) for nurses.

Differences between the evaluations of the CFS-EN and CSF-FR were not different from 0 , with a mean difference of $0.06(95 \% \mathrm{Cl}-0.24,0.36)$ for the EN version and $-0.03(95 \% \mathrm{Cl}-0.47,0.41)$ for the FR version. Average original version ratings were slightly lower than FR version ratings, though this difference did not reach significance: -0.29 $(95 \% \mathrm{Cl}-0.54,0.04)$.

Conclusion: In this prospective cohort of very old intensive care participants we developed and tested the basic psychometric properties (internal consistency, reproducibility) of a French version of the CFS. This manuscript provides clinically meaningful psychometric properties that have not been previously reported in any other language, including in the original EN version.

The French cultural adaptation of this CFS has adequate psychometric properties for doctors or nurses to evaluate frailty in very old intensive care patients.

Keywords: Older people, Frailty, ICU, Mortality, Severity of illness, Back-translation

\footnotetext{
* Correspondence: paul.abraham@unige.ch

${ }^{1}$ Department of Acute Care, Geneva University Hospitals, Geneva, Switzerland

${ }^{2}$ Faculty of Medicine and Science, Claude Bernard University, Lyon 1,

Villeurbanne, France

Full list of author information is available at the end of the article
}

(c) The Author(s). 2019 Open Access This article is distributed under the terms of the Creative Commons Attribution 4.0 International License (http://creativecommons.org/licenses/by/4.0/), which permits unrestricted use, distribution, and reproduction in any medium, provided you give appropriate credit to the original author(s) and the source, provide a link to the Creative Commons license, and indicate if changes were made. The Creative Commons Public Domain Dedication waiver (http://creativecommons.org/publicdomain/zero/1.0/) applies to the data made available in this article, unless otherwise stated. 


\section{Introduction}

As Europeans continue to experience increasing lifespans, surgical and perioperative care for the old $(>65)$ and very old ( $>80$ years) patients has become commonplace, and is expected to continue to increase in volume and complexity in future decades. Advanced age, as a risk factor in surgery, is the complex combination of an increased probability of comorbidities and "frailty". Frailty is an insufficiently understood decline in physiological reserve and resilience that may be related to energy production, energy utilization and defective repair mechanisms [1]. Frailty is strongly associated with increased mortality after intensive care (ICU) admission, even when controlling for chronological age and other risk factors [2].

To better understand the magnitude of the challenges involved in intensive care practice for an ageing population and discuss a rational allocation of resources, healthcare practitioners need a reliable evaluation of frailty [3]. There are multiple instruments to evaluate frailty with a diverse range of complexity, from the 70 items Frailty Index (FI) [4] to the more feasible clinical frailty scale (CFS) [5]. The latter, an ordinal 9-point visual scale in which the assessor makes decisions about the degree of frailty from clinical data, is well correlated with the FI $(r=0.80)$, but much easier to conduct [5]. The score ranges from very fit $(\mathrm{CFS}=1)$ to very severely frail $(\mathrm{CFS}=8)$ and terminally ill $(\mathrm{CFS}=9)$ (Fig. 1). Frailty is usually defined as CFS $>4$ [6].

Frailty assessment using tools such as the CFS should be part of the standard multimodal evaluation routinely performed in older adults [5]. However, after a literature search we were only able to identify the original English (EN) version of the CFS validation, thereby limiting its use by clinicians from other native languages. The use of the EN version or a non-validated translation of the CFS by healthcare personnel can result in different assessments and contribute to biases. Items could be answered differently because of differences in translation or culture instead of differences in actual patients' status, which can lead to inadequate scoring of frailty. Therefore, in order to promote the adequate use of this scale

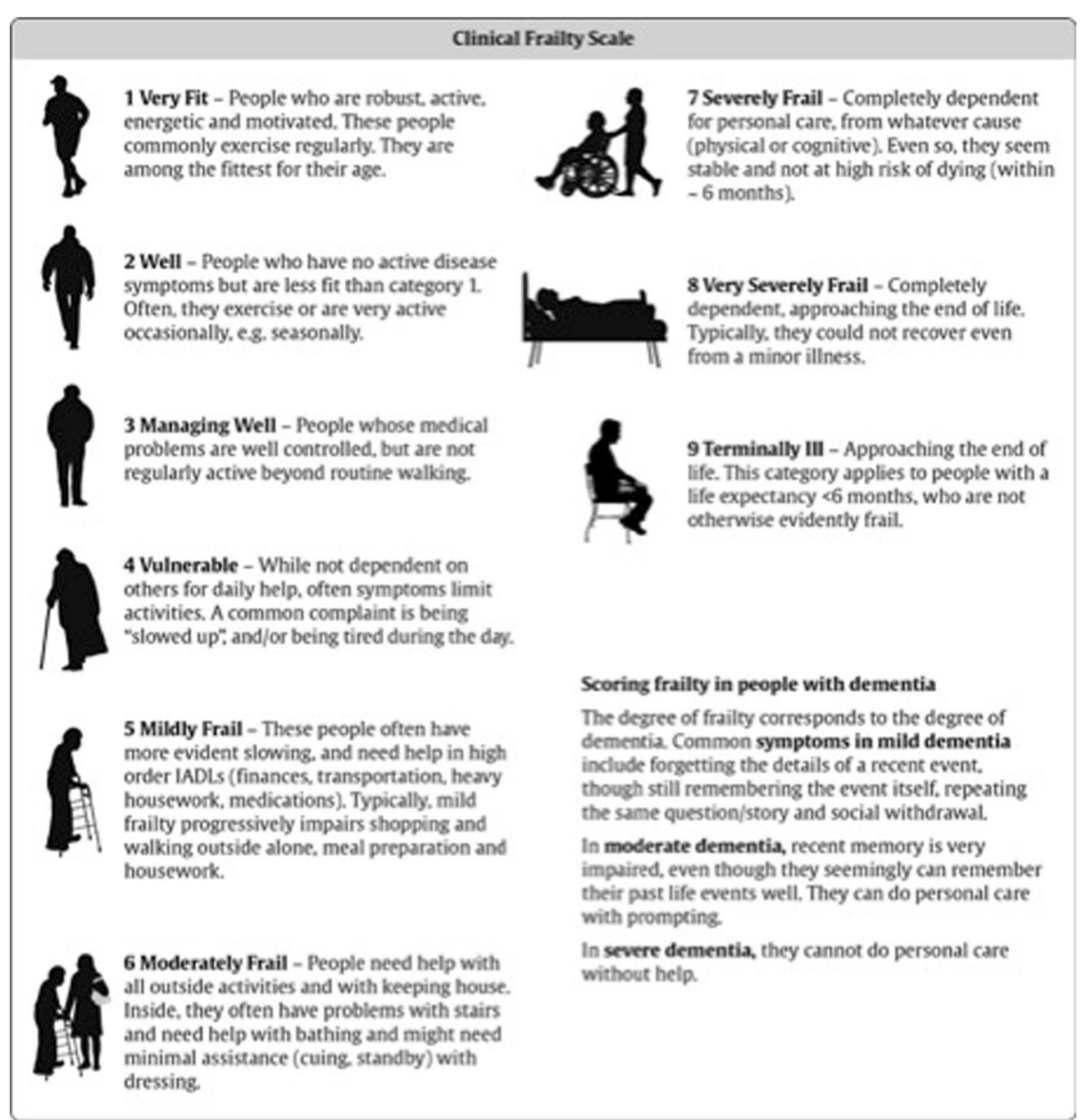

Fig. 1 Clinical Frailty Scale, Original EN Version (CFS-EN-original). Permission to use the CSF was granted from Dalhousie University, Ca. May 15. 2017 
in a wider panel of countries, we aimed to develop, validate and characterise a French (FR) version of the CFS.

\section{Methods}

We included participants recruited prospectively for the observational "The very old intensive care patient: A multinational prospective observation study" (VIP Study) [3] in the Intensive Care and Peri-Interventional Intermediate Care Units at Geneva University Hospitals (FR speaking hospital), between January and July 2017. The study was approved by the Geneva Regional Ethics Committee (Commission cantonale d'éthique de la recherche de Genève, CCER: 2016-01773, President: Professor Bernard Hirschel) that waived the need for informed consent. Observational data were collected according to international ethics standards conforming to the Declaration of Helsinki [7].

\section{Obtaining a French version for testing}

The translation from EN to FR was made in 4 steps by 4 clinicians (2 doctors and 2 nurses) with C2 (Europass) level of both languages, whose native language is FR. The text was then back-translated into EN by 2 independent clinicians (doctor and nurse) with the same language skills whose native language was EN. They were blinded to the original EN version. All translators were aware of the study design.

The original EN (CFS-EN) and EN back-translated versions were then compared qualitatively. Differences or incoherence between the two versions (CFS-EN original and EN-back-translated) were resolved by agreement in order to improve the French translated version.

The FR version was then further assessed by 5 Healthcare workers whose native language is French (nurses and doctors) working in the Geneva intensive or intermediate care units. Their feedback was used to further modify the scale and obtain the definite FR translated version (CFS-FR).

\section{Characterizing and validating the FR-final version}

The CFS was evaluated twice on the same participants with at least a 2-week interval. Evaluators were either of the same profession (nurse or physician) or of differing profession, to assess interjudge agreement within and between professions. The CFS was also assessed twice by the same evaluators, to evaluate test-retest reliability. Furthermore, the scale used was either in the same language or of differing language, to assess whether the ratings were similar with the French, compared to the English version of the scale. Doctors evaluated the

\section{Score de Fragilité Clinique}

1

1 Très en forme - Personnes qui sont robustes, actives énergiques et motivées. Ces personnes font de l'exercice régulièrement. Ils sont parmi les plus en forme de leur âge.

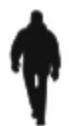

2 Bien - Personnes qui ne présentent aucun symptôme de maladie active mais sont moins en forme que la catégorie 1. Font souvent, des exercices ou sont très actives par période. (par exemple des variations saisonnières).

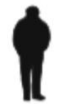

3 Assez bien - Personnes dont les problèmes médicaux sont bien contrôlés, mais ne sont pas régulièrement actives au-delà de la marche quotidienne.

4 Vulnérable - Sans être dépendantes des autres pour l'aide quotidienne, souvent leurs symptômes limitent leurs activités. Une plainte fréquente est d'être ralentie et/ou d'être fatiguée pendant la journée.

5 Légèrement fragile - Personnes qui ont souvent un ralentissement plus évident, et ont besoin d'aide dans les activités d'ordre élevé de la vie quotidienne (finances, transport, grosses tâches ménagères, médicaments). Généralement, la fragilité légère empêche progressivement de faire les courses, de marcher seul dehors, de préparer les repas et de faire le ménage.

6 Modérément fragile - Personnes qui ont besoin d'aide pour toutes les activités à l'extérieur et pour l'entretien de la maison. A l'intérieur, elles ont souvent des problèmes pour monter/descendre les escaliers, ont besoin d'aide pour prendre un bain et pourraient avoir besoin d'une aide prendre un bain et pourraient avoir bes
minimale (être à coté) pour s'habiller.

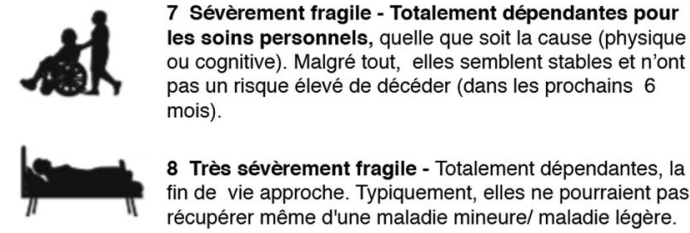

9 En phase terminale - Approchant la fin de vie. Cette catégorie concerne les personnes ayant une espérance de vie $<6$ mois, qui sinon ne sont pas fragiles de façon évidente.

\section{Classification de la fragilité des personnes atteintes de démence.}

Le degré de fragilité correspond au degré de démence.

Les symptômes courants de démence légère inclus : l'oubli des détails d'un événement récent mais le souvenir que l'événement a eu lieu, la répétition de la même question / histoire et le retrait social.

Dans la démence modérée, la mémoire récente est très altérée, même si les personnes peuvent bien se rappeler des événements de leur vie passee. Ils peuvent faire des soins personnels avec incitation.

Dans la démence grave, elles ne peuvent pas faire les soins personnels sans aide. 
English version twice and nurses evaluated the French version twice. Evaluators were blinded to each other's evaluation.

Criterion validity was assessed by examining the relation of CFS-EN and CFS-FR with mortality at 30-days after ICU admission, using Wilcoxon rank sum test.

Interjudge reliability and test-retest reliability were assessed using intraclass correlation (ICC) and Bland and Altman plot. ICC inter-rater agreement measures were considered poor - Less than 0.40, fair - Between 0.40 and 0.59, good - Between 0.60 and 0.74, excellent Between 0.75 and 1.00 [8].

\section{Results}

Of the 40 participants recruited to the VIP1 study, the CFS evaluation was performed in 34 participants. In 6 (15\%) participants, one or more operators were not able to provide a score due to insufficient data on participant health status prior to ICU admission. These 6 participants were excluded from further analysis. Mortality follow up was completed for all participants. Participants were mostly female (57\%) and were on average 84.1 years old.

Inter-rater reliability was 0.87 (95\%CI: 0.76-0.93) between doctors for the EN version (Fig. 1), and 0.76 (95\%CI: 0.57-0.87) between nurses for the FR version
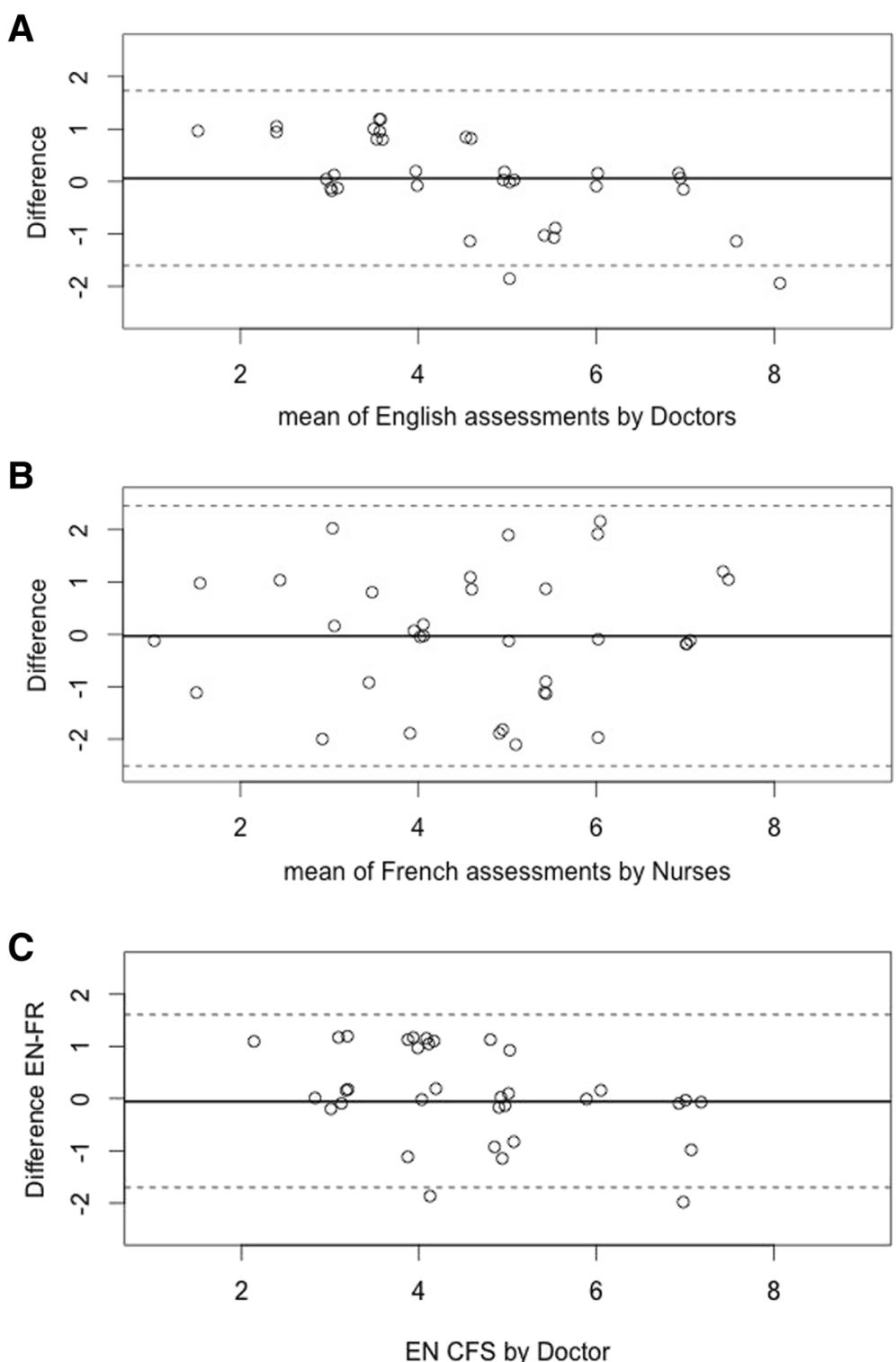

Fig. 3 Bland et Altman plot for CFS scoring between 2 independent Doctors with CFS-EN (a), between 2 independent Nurses with CFS-FR (b), with the EN then FR version by Doctor (c) 
(Fig. 2). Inter-rater variability between doctor and nurse was 0.75 (95\%CI: 0.56-0.87) for the EN version, and 0.73 (95\%CI: 0.52-0.85) for the FR version.

Test-retest (stability) with the EN vs the FR version was 0.86 (95\%CI: $0.72-0.93)$ for doctors and 0.87 (95\%CI: 0.76-0.93) for nurses.

Differences between the evaluations of the CFS-EN and CSF-FR were not different from 0 , with a mean difference of 0.06 (95\%CI -0.24-0.36) for the EN version and -0.03 (95\%CI -0.47-0.41) for the FR version (Fig. 3a, b). Agreement between the FR and the EN version for doctors was similar (Fig. 3c). Average English version ratings were slightly lower than French version ratings, though this difference did not reach significance: -0.29 (95\%CI -0.54-0.04).

There were 15 deaths within 30-days of ICU admission. There were no significant differences in the CFS scores between participants who died within 30 days and participants who survived for either the EN (median survived: 4.7 , median died: $4.0, p=0.52$ ) or FR (median survived: 4.7 , median died: $4.5, p=0.56$ ) versions.

\section{Discussion}

Overall, the EN and FR versions of the CFS exhibited good to excellent interjudge reliability, between doctors, between nurses, and to a lesser extent between nurses and doctors [8]. The test retest of either the FR or the EN versions showed a good stability. Bland and Altman representation showed a good agreement between doctors (see Fig. 3a).

Only 2 measures differed by more than 2 points with the CFS-EN scale performed by 2 independent doctors. Agreement between nurses with the FR version was fair (see Fig. 3b). Moreover, agreement between the FR and the EN versions for Doctors seemed strong enough to validate this EN-to-FR translation in clinical practice (see Fig. 3c).

As expected, the CFS scores were slightly higher in participants who died than in those who survived, though significance could not be achieved in this small cohort.

This study has some limitations. This is a report of a simple study using a standard forward-back translation method to develop and test a French version of an English questionnaire. The characterization and validation the FR-final version was performed in a relatively small number of participants, as this was a convenience sample using patients enrolled in the larger VIP1 study in Geneva University Hospitals. However, our sample size of 40 patients would allow us to detect an ICC of 0.75 with a half-confidence interval width of 0.25 . In 6 patients one or more operators were not able to provide a score due to insufficient data, thus raising the possibility of selection bias. Importantly, all values from the CFS except 9 are represented in the sample; hence in our opinion it is unlikely that the missing patients have an important influence in the validation study considering the range of analyses performed.

\section{Conclusion}

In this prospective cohort of very old intensive care participants we developed and tested the basic psychometric properties (internal consistency, reproducibility) of a French version of the CFS. This manuscript provides clinically meaningful psychometric properties that have not been previously reported in any other language, including in the original EN version [5]. The French cultural adaptation of this CFS has adequate psychometric properties for doctors or nurses to evaluate frailty in very old intensive care patients.

\section{Abbreviations}

CFS: Clinical frailty Scale; Cl: Confidence Interval; EN: English; Fl: Frailty Index; FR: French; ICC: Intraclass correlation; ICU: Intensive care unit

\section{Acknowledgements}

Not applicable.

\section{Authors' contributions}

PA DC and BP recorded analyzed and interpreted the participant data. DC gave methodology, statistical support and analysis, PA, BP, CL, TM, FD performed the forward and back-translation methodology. CA, KB, BW were major contributors in writing the manuscript. HF RM SC DDL BG gave insightful comments and critical review of the manuscript. All authors read and approved the final manuscript.

\section{Funding}

Not applicable.

\section{Availability of data and materials}

The datasets used and/or analysed during the current study are available from the corresponding author on reasonable request.

\section{Ethics approval and consent to participate}

The study was approved by the Geneva Regional Ethics Committee (Commission cantonale d'éthique de la recherche de Genève, CCER: 201601773, President: Professor Bernard Hirschel) that waived the need for informed consent. Observational data were collected according to international ethics standards conforming to the Declaration of Helsinki.

\section{Consent for publication}

Not applicable.

\section{Competing interests}

The authors declare that they have no competing interests.

\section{Author details}

'Department of Acute Care, Geneva University Hospitals, Geneva, Switzerland. ${ }^{2}$ Faculty of Medicine and Science, Claude Bernard University, Lyon 1, Villeurbanne, France. ${ }^{3}$ Geneva Hemodynamic Research Group, University of Geneva, Geneva, Switzerland. ${ }^{4}$ Quality of care unit, Geneva University Hospitals, Geneva, Switzerland. ${ }^{5}$ Department of Geriatric Medicine, Angers University Hospital; Angers University Memory Clinic; Research Center on Autonomy and Longevity; UPRES EA 4638, University of Angers, Angers, France. ${ }^{6}$ Department of Medical Biophysics, Robarts Research Institute, Schulich School of Medecine and Dentistry, the University of Western Ontario, London, ON, Canada. ${ }^{7}$ Department of Anaesthesia and Intensive Care, Haukeland University Hospital, Bergen, Norway. ${ }^{8}$ Unidade de Cuidados Intensivos Neurocríticos, Hospital de São José, Centro Hospitalar de Lisboa Central, Faculdade de Ciência Médicas de Lisboa, Nova Médical School, Lisbon, Portugal. ${ }^{9}$ Department of Anaesthesia and Intensive Care Medicine, Aarhus University Hospital, Aarhus, Denmark. ${ }^{10}$ Department of Intensive Care 
Medicine, University Medical Center, University Utrecht, Utrecht, The Netherlands. " Assistance Publique-Hôpitaux de Paris, Hôpital Saint-Antoine, service de réanimation médicale, Paris, France. ${ }^{12}$ Sorbonne Universités, UPMC Univ Paris 06, Institut Pierre Louis d'Epidémiologie et de Santé Publique, Paris, France. ${ }^{13}$ INSERM, Institut Pierre Louis d'Epidémiologie et de Santé Publique, Paris, France. ${ }^{14}$ Geneva Perioperative Basic, Translational and Clinical Research Group, Division of Anaesthesiology, Geneva University Hospitals, Geneva, Switzerland.

Received: 25 July 2019 Accepted: 11 October 2019

Published online: 21 November 2019

\section{References}

1. Clegg A, Young J, lliffe S, Rikkert MO, Rockwood K. Frailty in elderly people. Lancet Lond Engl. 2013;381(9868):752-62.

2. Baldwin MR, Narain WR, Wunsch H, Schluger NW, Cooke JT, Maurer MS, et al. A prognostic model for 6-month mortality in elderly survivors of critical illness. Chest. 2013;143(4):910-9.

3. Flaatten H, De Lange DW, Morandi A, Andersen FH, Artigas A, Bertolini G, et al. The impact of frailty on ICU and 30-day mortality and the level of care in very elderly patients ( $\geq 80$ years). Intensive Care Med. 2017;43(12):1820-8.

4. Saxton A, Velanovich V. Preoperative frailty and quality of life as predictors of postoperative complications. Ann Surg. 2011;253(6):1223-9.

5. Rockwood K, Song X, MacKnight C, Bergman H, Hogan DB, McDowell I, et al. A global clinical measure of fitness and frailty in elderly people. CMAJ Can Med Assoc J. 2005:173(5):489-95.

6. Juma S, Taabazuing M-M, Montero-Odasso M. Clinical frailty scale in an acute medicine unit: a simple tool that predicts length of stay. Can Geriatr J CGJ. 2016;19(2):34-9.

7. WMA Declaration of Helsinki - Ethical Principles for Medical Research Involving Human Subjects. 2013 [cited 2016 Oct 27]. Available from: http:// www.wma.net/fr/30publications/10policies/b3/

8. Cicchetti DV. Guidelines, Criteria, and Rules of Thumb for Evaluating Normed and Standardized Assessment Instruments in Psychology. Psychol Assess. 1994;6(4):284-90.

\section{Publisher's Note}

Springer Nature remains neutral with regard to jurisdictional claims in published maps and institutional affiliations.

Ready to submit your research? Choose BMC and benefit from:

- fast, convenient online submission

- thorough peer review by experienced researchers in your field

- rapid publication on acceptance

- support for research data, including large and complex data types

- gold Open Access which fosters wider collaboration and increased citations

- maximum visibility for your research: over $100 \mathrm{M}$ website views per year

At $\mathrm{BMC}$, research is always in progress.

Learn more biomedcentral.com/submissions 